\title{
A CIDADE SOBRe A CIDADE: O PLANO DE ANTONIO BONET PARA A ÁREA SUL DE BUENOS AIRES, $1956^{1}$
}

\section{The City Over The City: The Antonio Bonet's Plan For The South Area Of Buenos Aires, 1956}

\author{
Helena Bender \\ Pós-graduação em Arquitetura, Universidade Federal do Rio Grande do Sul \\ bender.helena@gmail.com
}

\section{Resumo}

Este artigo examina o Plano de Remodelação da Área Sudeste de Buenos Aires (1956), proposto por Antonio Bonet, entendendo-o como projeto que coloca discussões importantes ao estudo da cidade moderna. Pela pesquisa bibliográfica, tem-se que o projeto defende a habitação como programa importante a existir no centro da cidade, sendo articulado por outros, como trabalho e lazer. A cidade existente é o ponto de partida da proposição, e é reconfigurada em três elementos - a torre, a greca, e o edifício baixo. Este último se torna um elemento importante, capaz de controlar a área verde, e de formalizar uma rede pedestre. Desta forma, o plano continua uma investigação anterior ao estabelecer novamente um sistema que interliga as escalas da cidade e da paisagem, do bairro e da habitação.

\section{Palavras-chave}

Barrio Sur, Antonio Bonet Castellana, cidade moderna, habitação coletiva.

\begin{abstract}
This article examines the Plan for Barrio Sur (1956), proposed by Antonio Bonet to the city of Buenos Aires, understanding it as a contribution that inserts important notions to the study of the modern city. The bibliographic research revealed that the plan defends housing as an important program to exist in the city center, being supported by others, as working and leisure. The existing city is the starter point of the proposal, and it is reshaped into three building types - the tower, the greca, and the low-rise building. The last one becomes an important element, capable of controlling the amount of green area, and of formalizing a pedestrian network. Therefore, the plan
\end{abstract}

\footnotetext{
${ }^{1} \mathrm{O}$ texto foi originalmente apresentado no $3^{\circ}$ Congresso Internacional de História Urbana, celebrado em Brasília, no período de 25 a 30 de novembro de 2013.
} 
continues a previous investigation, establishing again a system that links the scales of the city and the landscape, of the neighborhood and the housing.

\section{Keywords}

Barrio Sur, Antonio Bonet Castellana, modern city, collective housing.

\section{Introdução}

Gorelik (2010) aponta como resultado do desenvolvimento urbano da cidade de Buenos Aires um desequilíbrio entre as direções Norte e Sul, porções que o eixo formado pela Avenida de Mayo coloca como originalmente simétricas. O autor explica que as diferenças de desenvolvimento entre estas direções são reforçadas por características políticas e sociais opostas, que colocam a porção Norte como a "cidade elegante", e que detém a preferência dos investimentos da iniciativa privada e de ações da municipalidade; e a porção Sul como a "cidade operária", dos protestos, e urbanisticamente estagnada. Como resposta a este desequilíbrio, o sul será o escopo de intervenção por parte da municipalidade a partir do século XX (GORELIK, 2010, p. 199; 200), e como exemplo significativo se pode citar o início das obras de construção da Avenida 9 de Julio pelo intendente Mariano de Vedia em 1937.

A assimetria norte-sul é também percebida por Le Corbusier, Jorge Ferrari Hardoy e Juan Kurchan no Plano Diretor para Buenos Aires (1938-40). Entre as intenções do plano, de "transformação molecular da cidade" e de "concentrar a cidade", o "despertar do sul" é uma das articulações importantes da proposta, que procura implantar ao sul da linha divisora, os equipamentos destinados para instituições e para o governo, com a finalidade de promover algum equilíbrio com o desenvolvimento do Norte (LE CORBUSIER et al., 1947). Os autores reivindicam que a área apresenta uma localização vantajosa, muito próxima do "centro vital da cidade" em que se distribuem os negócios e serviços, aspecto a ser reforçado pela proposição (LE CORBUSIER et al., 1947, p. 29).

Seguindo esta mesma motivação, o Plano de Remodelação da Área Sudeste da Capital Federal (1956), comumente nomeado pelos críticos e historiadores de "Plano para o Barrio Sur", se junta a este contexto propositivo e também político de valorização do sul. O plano abrange a área de um dos setores mais antigos de Buenos Aires, e adota a habitação como principal programa, cujo lugar se dá fundamentalmente na parte central da cidade. Segundo seu autor, o arquiteto Antonio 
Bonet Castellana ${ }^{2}$, o plano nasce precisamente desta relação não equilibrada entre Norte e Sul:

[O plano] Surgiu de uma conferência que eu dei em Buenos Aires sobre urbanismo, propondo várias coisas, entre elas, que tinha que ser feito algo para evitar o desequilíbrio que havia entre o Bairro Sul e o Bairro Norte. [...]. Logo desta conferência me chamou o então presidente do Banco Hipotecário Nacional e me falou de fazer e estudar um projeto com uma proposta de delimitação. $^{3}$ (BONET, 1978 in KATZENSTEIN et al., 1985, p. 95, tradução nossa).

Para o presidente do Banco Hipotecário Nacional, Manoel Rawson Paz, Antonio Bonet era o arquiteto capaz para conduzir o plano de remodelação. Em 1956, Bonet contava com um histórico importante de projetos em que se cruzam os temas cidade e habitação, além de sua trajetória profissional ter sido relacionada de forma contínua a debates engajados com temas sobre a cidade moderna ${ }^{4}$.

O plano seria possível através de uma parceria entre a municipalidade e a iniciativa privada, a ser construído por etapas organizadas ao longo de dez anos de obra, admitindo-se a participação de diferentes arquitetos e construtoras no processo. O plano consiste em uma pauta, uma estrutura orientadora concebida "de forma suficientemente elástica para permitir o livre jogo das forças cidadãs", e ao mesmo tempo caracterizando "uma estrutura capaz de se sustentar através das variações possíveis e de preservar esse algo indefinido que constitui o feito cidade" (BONET apud RAMOS, 1956, p. 38, tradução nossa). Assim, o plano não se configura como uma proposta acabada, necessariamente rígida, mas como um planejamento que admite graus de interferência.

Entretanto o plano de remodelação para o Barrio Sur nunca foi concretizado. Por sua dimensão e localização, movimentou importantes discussões na época entre os habitantes e organizações que se mobilizaram em passeatas e matérias na imprensa. Destaca-se aqui que estas manifestações ocorreram em um contexto de

\footnotetext{
2 Para formulação do plano, colaborou com Antonio Bonet a seguinte equipe: Luis H. Aberastain Oro, Horacio Baliero, Nélida Gurevich, Eduardo Polledo, Próspero E. Poyard, Victor Sigal, César A Vapñarsky e Severo A. Yantorno (arquitetos); Jorge A. Martucci (engenheiro); Osvaldo Lauersdorf (agrimensor); Eduardo Bell, Oscar N. Candioti, Raúl Pastrana (maquetes); Carmem Córdova de Baliero, Carlos Castiglione, Carlos E. Dourge, Justo J. Solsona, Fernando L. Tiscornia (desenhos). Alfredo Hlito (graficação), e Aníbal G. Larumbe (fotografia). (BONET, 1957, p. 63).

3 "Surgió de una conferencia que yo di en Buenos Aires sobre urbanismo, proponiendo varias cosas entre ellas que había que hacer algo para evitar el desequilibrio que había entre el Barrio Sur y el Barrio Norte. [...]. Luego de esa conferencia me llamó el entonces presidente del Banco Hipotecario Nacional y me habló de hacer y estudiar un proyecto con una propuesta de delimitación."

${ }^{4}$ Para saber mais sobre obra de Antonio Bonet, ver: ALVAREZ, Fernando; ROIG, Jordi. Antoni Bonet Castellana 1913-1989. Barcelona: Colegio de Arquitectos de Catalunya/ Ministério de Fomento, 1996. $227 \mathrm{p}$.
} 
conflito político entre forças da resistência peronista e do governo provisório instaurado pela Revolução Libertadora. Liernur comenta na conclusão de seu artigo Las villas miseria, el Barrio Sur y la Revolución Libertadora (2011), que apesar da natureza moderna o plano surge como um "instrumento anacrônico", já que uma operação de tamanha envergadura não poderia ser encabeçada por um governo provisório e num momento de instabilidade entre forças opostas:

[...] em suas direções contraditórias, de conservadores e modernizadores, de esquerdistas e liberais, as novas dinâmicas sociais que as ideias do Plano puseram em movimento faziam impossível sustentá-lo baseado naquele poder efêmero instalado depois da derrubada do governo do General Perón. O lema da elevação contra uma suposta "ditadura" - e por onde a reivindicação de formas democráticas embora só fosse parcial e retórica - era totalmente contraditória à dinâmica que uma proposta como essa requeria. ${ }^{5}$ (LIERNUR, 2011 , p. 98, tradução nossa).

Sobre tal instabilidade política, Bonet também afirma em entrevista: "Nenhum regime logo da queda de Perón durou o suficiente para fazer uma verdadeira obra de remodelação urbana, que é muito profunda socialmente e economicamente, ainda longa e difícil." (BONET, 1978 in KATZENSTEIN et al., 1985, p. 96, tradução nossa) (Fig.1).
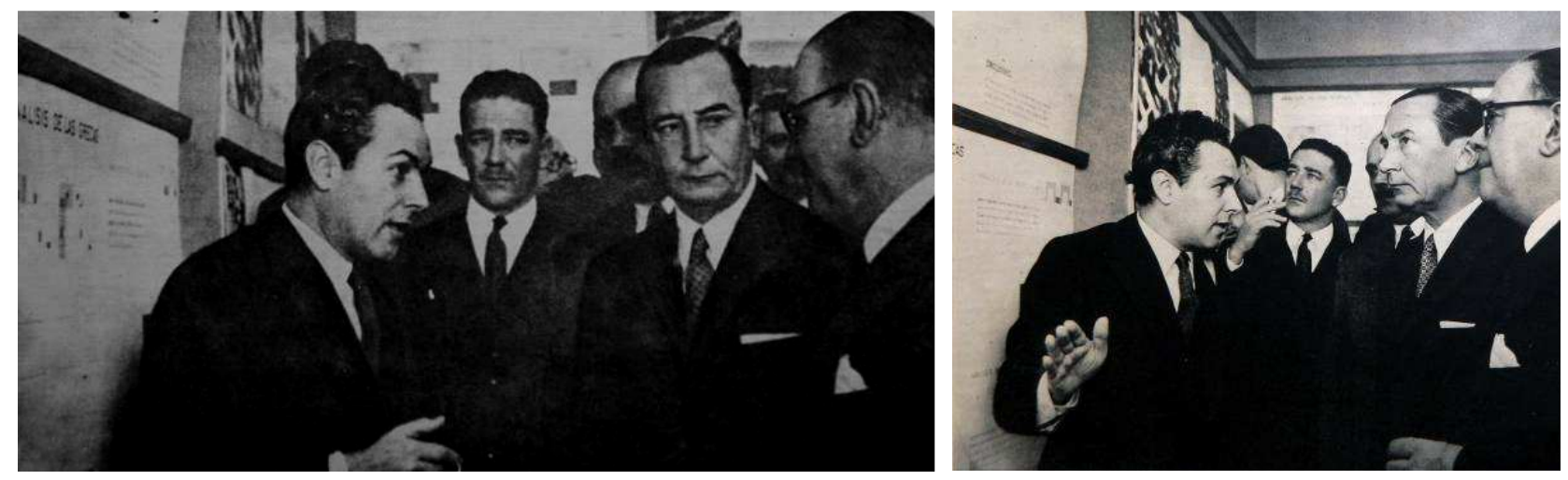

Figura 1 - Exposição do Plano de Remodelação para o Barrio Sur. Da esquerda para a direta: Antonio Bonet, o Ministro da Aeronáutica Julio C. Krause, o Presidente do Banco Hipotecário Nacional Manoel Rawson Paz, o Presidente Pedro Eugenio Aramburu, e o Prefeito de Buenos Aires Luis María de la Torre. Fonte: ESTO ES, 1956, p. 24; MUNDO HISPÁNICO, 1956, p. 15

\footnotetext{
5 " $[. .$.$] en sus direcciones contradictorias, de conservadores y modernizadores, de izquierdistas y$ liberales, las nuevas dinámicas sociales que las ideas del Plan pusieron en movimiento hacían imposible sostenerlo basado en aquel efímero poder instalado tras el derrocamiento del gobierno del General Perón. La consigna de alzamiento contra una supuesta 'dictadura' - y por ende la reivindicación de formas democráticas, aunque solo fuera parcial y retórica - era totalmente contradictoria con la dinámica que una propuesta como esa requería."
} 
Se em termos políticos, e enquanto obra a ser construída, o plano surgiu fora de seu tempo, no âmbito da cidade moderna, e enquanto projeto, coloca discussões pertinentes. Além de conceber a habitação como programa importante a existir no centro da cidade, e por trás da ideia de revitalização do sul, uma das principais preocupações demonstradas pelo plano circunda uma ideia de revisão de escalas, no sentido das relações estabelecidas entre as partes componentes da cidade. Desta forma, o projeto de Bonet continua uma investigação anterior, colocada por ele, Jorge Vivanco e Jorge Ferrari Hardoy no Plano para Bajo Belgrano em 1949, ao estabelecer novamente um sistema pedestre que interliga as escalas da cidade e da paisagem, do bairro e da habitação. Em relação ao projeto de Bajo Belgrano, esta questão foi recentemente explorada por Cláudia Cabral no artigo Uma máquina para jogar em Buenos Aires 1938-1978 (2012), e este texto visa dar continuidade a esta investigação, sustentando que o projeto para o Barrio Sur faz avançar o sistema de Bajo Belgrano pela introdução de novos elementos. Em relação ao método, este trabalho foi realizado considerando as etapas: a) pesquisa bibliográfica sobre a obra e os temas que a cercam; b) análise e síntese do material pesquisado; e c) redesenho do material gráfico publicado para melhor compreensão do projeto.

\section{A cidade sobre a cidade}

A área delimitada por Antonio Bonet para a remodelação é circundada pelas avenidas Paseo Colón e 9 de Julio a Leste e Oeste, pela Avenida Belgrano a Norte e as ruas Caseros, Brasil e Defensa a Sul. Em sentido Norte e Sul, é próxima a Plaza de Mayo, e faz limites com o Parque Lezama, incluindo-o como área complementar do projeto (BANCO HIPOTECARIO NACIONAL, 1956); e no sentido Leste se limita com o porto e o Rio da Prata, elementos importantes para a cidade e para a escolha do sítio. A área abrange cerca de 110 quadras do damero portenho a serem remodeladas (Fig. 2). O termo remodelação utilizado, que serve para caracterizar a natureza do projeto desde seu título, implica a ideia de refazer algo seguindo outra direção, introduzindo modificações importantes com relação ao existente: em termos de programa, coloca a habitação como problema que ocupa uma posição central com relação à cidade e não periférica; e em termos de forma, altera a dimensão da quadra tradicional, cujas divisões do lote são suprimidas e convertidas em elementos arranjados em uma nova ordem compositiva (Fig. 3). 

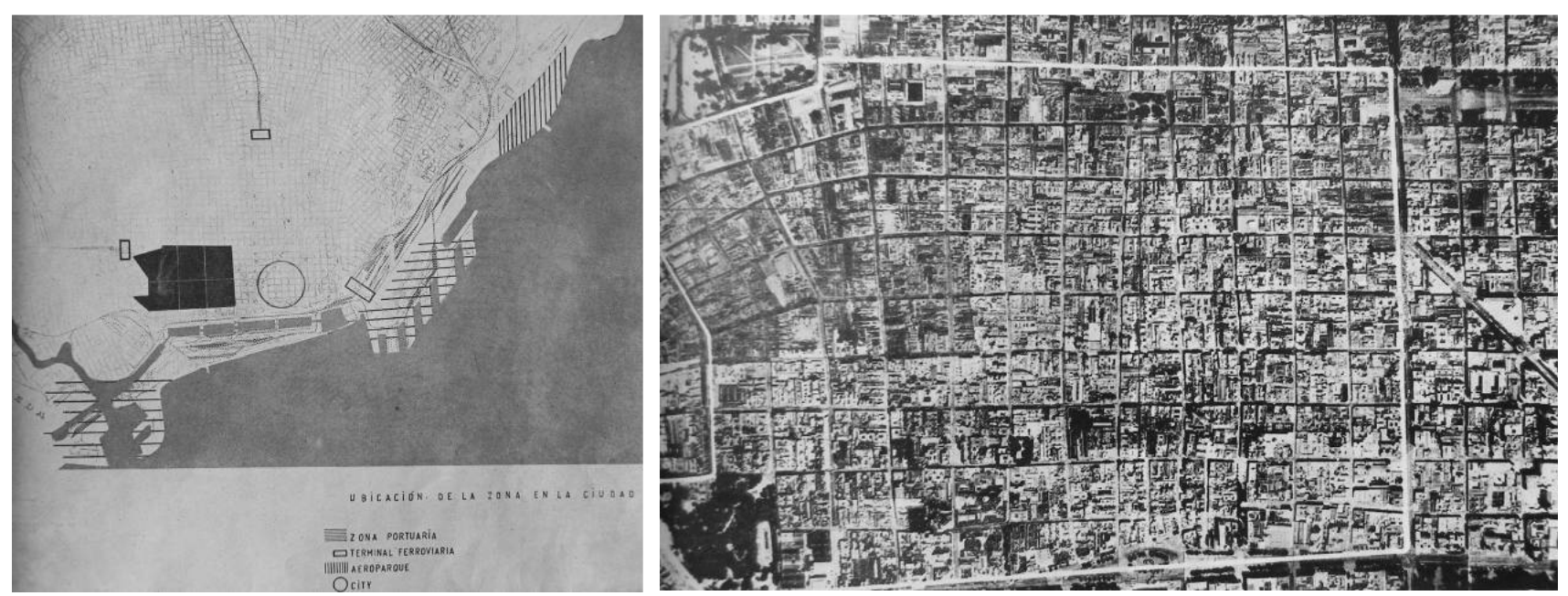

Figura 2 - Da esquerda para a direita: localização do plano, e aerofotografia de situação existente à época.

Fonte: BHN, 1957

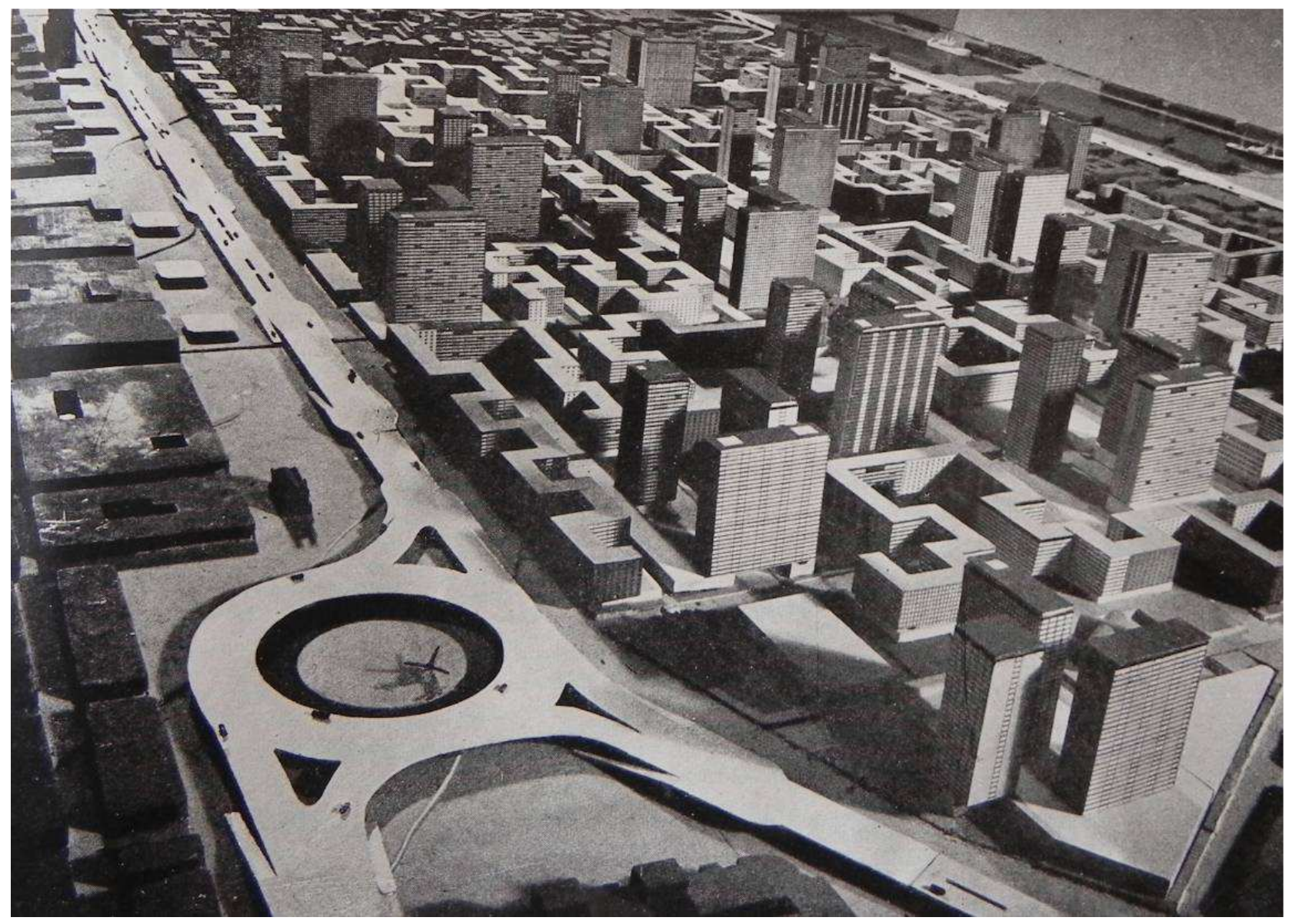

Figura 3 - Maquete do Plano de Remodelação para o Barrio Sur.

Fonte: $\mathrm{BNH}, 1957$ 
O projeto foi calculado para abrigar uma população de 450 mil pessoas no centro de Buenos Aires, em vez dos 80 mil da época ${ }^{6}$ (RAMOS, 1956, p. 37), reivindicando esta posição na cidade como o local legítimo de moradia, trabalho e também de lazer. Sustentando que "o cidadão deve viver na cidade, não fora dela" (BHN, 1957, tradução nossa) o projeto se opunha a localizar a habitação em algum lugar a urbanizar, ou distante dos locais de intensa vida urbana, de modo contrário à prática iniciada pela política da época. A política para a habitação começada após o golpe de 1955 propunha resolver o problema do aumento populacional das "vilas" na região metropolitana pelo translado desta população para áreas ainda mais distantes, ou por sua formalização ali mesmo. Ainda que a ideia fosse a de fazer uso de uma organização de maior densidade nessas localizações, como o uso do bloco habitacional em vez da tipologia da casa isolada, as áreas não contavam com uma infraestrutura adequada, o que aumentava o custo unitário da habitação (YUJNOVSKY, 1974, p. 18). Neste contexto, o projeto para o Bairro Sur surge como crítica deste procedimento ao mesmo tempo em que se coloca como uma possível solução, já que a ideia era a do aproveitamento mais racional da estrutura já existente na cidade constituída, de acessibilidade a comércios e serviços, corrigindo os deslocamentos congestionantes entre habitação e trabalho ao condensar a cidade sobre si mesma. Ressalta-se que o distanciamento entre estes dois elementos de programa - habitação e trabalho - é algo evitado na obra de Bonet, independente de sua natureza, sendo exemplos desta afirmação tanto o edifício de ateliês na esquina das ruas Paraguay e Suipacha, que Bonet realiza junto dos arquitetos Vera Barros e Lópes Chas, quanto seu texto Nuevas precisiones sobre arquitectura y urbanismo (1949), em que cita como princípio a "relação perfeita" entre estas duas dimensões.

Como crítica à cidade que ali está, a quadra é revisada, ampliando sua escala e dividindo a área total do plano em seis grandes setores equivalentes, de aproximadamente 16 hectares cada. A alteração da escala da quadra altera também seu caráter pedestre e veicular, mas a conserva como elemento ordenador e capaz de garantir a continuidade do sistema viário da nova cidade com a cidade existente (BONET, 1957, p. 69). Segundo o discurso do plano, a quadra de 100 passa a ter aproximadamente 400 metros de lado (BONET, 1957, p. 72), adotando a distância média de "400 metros" proposta por Le Corbusier (1971, p. 104) como modulação

\footnotetext{
${ }^{6}$ De acordo com o censo de 2001, a população aproximada da área é de pouco mais de 23 mil habitantes. (DIRECCIÓN GENERAL DE ESTADÍSTICA Y CENSOS, 2001). 
para o tráfego veicular da cidade moderna ${ }^{7}$. Esta medida incorpora 16 quadras existentes, o que elimina algumas ruas e adéqua outras, mais precisamente as avenidas San Juan e Independencia no eixo Leste-Oeste e a Rua Perú no eixo NorteSul. Em operação parecida, é possível citar o Plano Maciá para Barcelona (1933-35), desenvolvido por Le Corbusier, juntamente com o GATEPAC, que Bonet assiste no início de sua carreira (ALVAREZ in ALVAREZ; ROIG, 1996, p. 24). Nele a parcela urbana existente a ser investigada é o quarteirão de Cerdá, o qual também é amplificado: a cada três quadras de Cerdá, um novo arruamento é proposto, respeitando a mesma medida de 400 metros que é convertida em 16 hectares, ou nove quadras existentes (Fig. 4).
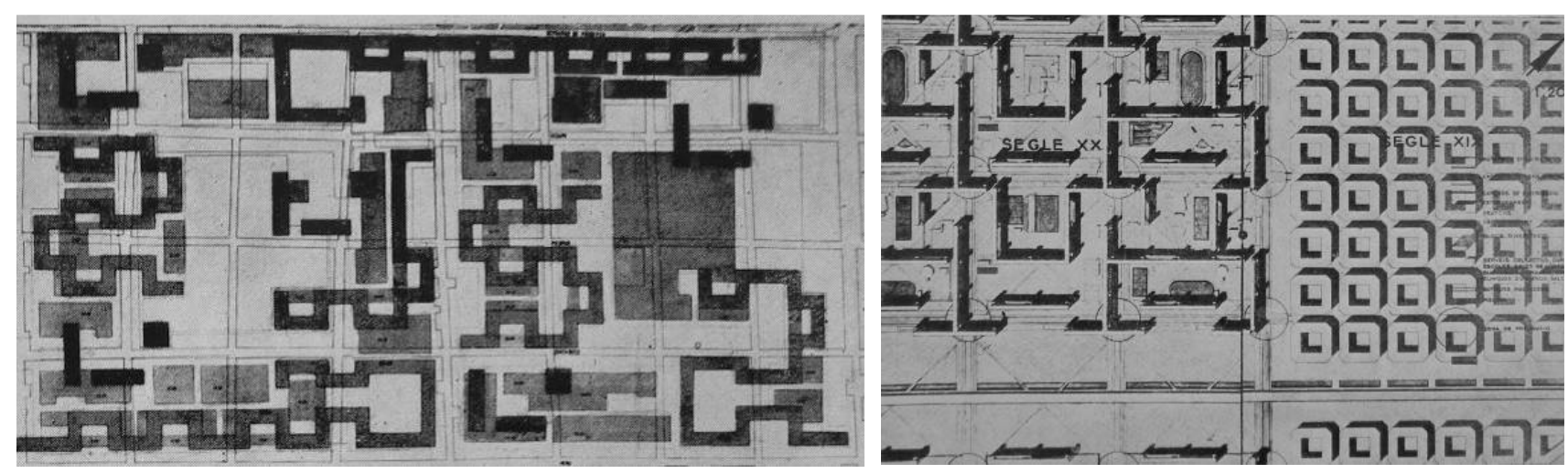

Figura 4 - Da esquerda para a direita: planta de trecho da proposta para o Barrio Sur, planta de trecho do Plano Maciá para Barcelona.

Fonte: BHN, 1957; BASTLUND, 1967, p. 33

A nova quadra proposta por Bonet pode ser entendida como um setor, ou "bairro" para utilizar um termo promovido pelo arquiteto ${ }^{8}$, e em termos de planta, seu esquema geral de organização propõe a articulação de duas forças que se complementam e ancoram o programa habitação. Ao centro, Bonet implanta edifícios de caráter administrativo e cultural, áreas verdes e de lazer de cada bairro; e para a periferia, posiciona o comércio, que configura o limite de cada bairro, bem como a continuidade por entre esses bairros e a cidade existente. Trata-se, segundo a explicação encontrada na memória descritiva do plano, de um "elemento centrípeto que dá ao bairro suas características próprias", articulado por um "elemento centrífugo que constitui uma força unificadora com a cidade", e que atinge o seu auge

\footnotetext{
7 "La división en lotes de 400 metros de lado determina, pues, barrios de 16 hectáreas con una población que oscila, según sea de negocios o residencial, entre 50.000 y 6.000 habitantes." (LE CORBUSIER, 1971, p. 104).

${ }^{8}$ Nos textos e nos desenhos, a primeira denominação é a de setor, mas logo é trocada por Bonet pela ideia de bairro, como no exemplo: "La zona a remodelar se divide en seis sectores [...] unidades urbanísticas autosuficientes denominadas 'barrios' de esta ciudad". (BONET, 1959, p. 11).
} 
nos cruzamentos entre os bairros (BHN, 1957, tradução nossa). Sobre esta organização, o que antes era ocupado pela quadra tradicional e seu loteamento é convertido em basicamente três peças distribuídas pelo território: edifícios altos e pontuais, de 100 metros de altura, ou 35 pavimentos (torres); edifícios médios e contínuos, de 30 metros de altura, ou 11 pavimentos $\left(\right.$ grecas $^{9}$ ); e edifícios baixos de até dois pavimentos ou seis metros de altura (vaca) (BHN, 1957). Juntos, estes elementos propõem três escalas distintas referidas respectivamente como "escala do espaço", "escala da árvore", e "escala do homem" (BONET, 1957, p. 76). Apesar das diferentes proporções e tipos empregados, os três modelos de edifícios são responsáveis pelo programa habitação, que é desenvolvido em altura e em organização coletiva, para um total de 75 mil habitantes por bairro, garantindo uma densidade de aproximadamente 4,7 mil habitantes por hectare. Como consta na memória do plano, a articulação destas três peças ordenadas de modo sistemático, permitiria uma variabilidade importante ao conjunto, ocasionando contrastes nos cenários urbanos gerados que não seriam possíveis pela eleição de uma única altura (BHN, 1957). Assim como a altura entre as três peças não é única, também não são suas orientações, demonstrando que uma possível geratriz do conjunto não tenha se dado a partir de um cálculo da melhor insolação, ou pela eleição da melhor altura, mas pela lógica ortogonal da quadra da cidade existente, numa tentativa compositiva de estabelecer relações tanto horizontais quanto verticais entre a nova cidade e estes alinhamentos urbanos.

Como imagem geral do sistema proposto, o edifício médio é entendido como o elemento que se expande, extravasando os limites do bairro para alcançar a escala da cidade. E o edifício alto, para alcançar a escala da paisagem, da vista do Rio da Prata. Ambos os elementos são geográficos em certa medida: um de domínio horizontal, outro de domínio vertical. Juntos compõem o ritmo do tecido urbano configurado que, de modo genérico, se dá ou sobre o verde, ou sobre o edifício baixo. Este último elemento adquire uma grande importância, pois é ele que responde ao nível do chão, à escala pedestre, e que ao se desenvolver é capaz de controlar o verde e domesticar o térreo desta versão de cidade moderna; e além, por constituir uma interface com o pedestre, organiza um sistema que serve de suporte para os edifícios médios e altos. Assim, o edifício baixo formaliza um sistema que o unifica com os demais, e se manifesta de modo concreto em uma rede movimento pedestre. Esta rede relaciona o térreo destes componentes edificáveis com os componentes do espaço aberto como

\footnotetext{
${ }^{9}$ O termo "greca" foi utilizado por Bonet para descrever o edifício médio. Assim, o termo foi deixado no idioma original, em espanhol.
}

URBANA, V.6, no 8, jun.2014 - Dossiê: Cidade e Habitação na América Latina - CIEC/UNICAMP 
praças, esplanadas e áreas vegetadas, e responde a uma organização mais ampla e complexa que perpassa a escala do pedestre e da cidade proposta e costura esta cidade sobre a cidade existente.

\section{A vaca, o pasto, a rede pedestre}

Insisti em dar importância a estes edifícios de um só piso criando ruas pedestres entre os comércios, escolas e bibliotecas. Primeiro traçamos as torres, logo a greca, e quando começamos com isso, eu comecei a ampliar. Alguém que estava ali disse "se está comendo o pasto". Como comia o pasto Ihe puseram o nome de vaca. Insisti em não criar espaços verdes excessivos, exatamente o oposto ao que havia feito uns anos antes em Bajo Belgrano. ${ }^{10}$ (BONET in BOBZIN, 1983, p. 46, tradução nossa).

Em contradição à banalidade do termo utilizado para caracterizar o edifício baixo - que é nomeado "vaca" - este componente ganha protagonismo na remodelação, pois é capaz de regrar a área verde da cidade proposta, e conectá-la a uma rede de movimento pedestre, fazendo prevalecer um caráter mais urbano. Além da habitação, a vaca responde a outros programas como os de caráter especial, de escolas e centros culturais, e ainda outros como comércios e serviços, capazes de articular uma movimentação pedestre importante no nível do térreo. Em relação ao "pasto", que se refere às áreas verdes, a dinâmica das forças "centrípeta" e "centrífuga", antes explicada, o estabelece como pivô na organização de cada bairro, ao centro, e com a atuação da vaca podemos entender estas áreas verdes como porções restantes da ocupação gradual da área do bairro. Em termos gerais, o verde deixa de ser natural e espontâneo nesta proposição para adquirir um caráter mais artificial e civil ao ser contido pela cidade proposta. Neste sentido, diferente de Bajo Belgrano, o plano para o Barrio Sur não representou segundo Bonet "o espaço verde como protagonista do urbanismo" (BONET, 1983, p. 46, tradução nossa), sendo este mais um elemento de espaço aberto que seu principal agente.

As manipulações da vaca, quanto à sua geometria e articulações com os edifícios médio e alto, respectivamente a greca e a torre, tem por consequência a produção de espaços abertos de tamanhos distintos, capazes de abrigar diferentes usos, bem como de incorporar elementos preexistentes. A mesma variedade reivindicada para as tipologias habitacionais é colocada em relação às diferentes

\footnotetext{
10 "Insistí en darle importancia a estos edificios de un solo piso creando calles de peatones entre los comercios, escuelas y bibliotecas. Primero trazamos las torres, luego la greca y cuando empezamos con esto lo empecé a ensanchar. Alguien que estaba allí dijo 'se está comiendo el pasto'. Como se comía el pasto le pusieron la vaca. Insistí en no crear espacios verdes excesivos, exactamente lo opuesto a lo que había hecho uno años antes en el Bajo Belgrano."
} 
escalas do espaço aberto, o que insere o projeto num rol de proposições que, segundo Bonet (1957, p. 69) se preocupam com uma "maior presença e adequação" desses espaços, coexistindo aqueles de grandes dimensões com os de menores. Por exemplo, para o verde de maior escala e central ao bairro atribui-se um caráter de parque por sua concentração (BHN, 1957), mas além dele há outras porções vegetadas, porém em menor escala e mais dispersas; o mesmo pode ser pensado quanto às esplanadas cívicas, que são áreas mais áridas e maiores que convivem com praças menores. Por não ser um elemento de geometria definida, existindo como um retângulo, um quadrado, ou alguma forma especial, a vaca facilita a incorporação de elementos preexistentes no projeto, como edifícios históricos ou aqueles de grande importância social a serem mantidos. Trata-se de um elemento maleável, a ser utilizado às vezes abaixo da greca e da torre, às vezes relacionado à preexistência, às vezes solto, dispersando-se e neutralizando o grande espaço aberto.

Como Cabral (2010, p. 96) aponta, o espaço aberto é um elemento importante para a caracterização dessas proposições, e por vezes é esquematicamente entendido apenas como a habitação estendida sobre o verde através de blocos independentes, fato que a autora contesta em relação ao projeto de Bajo Belgrano. Neste projeto, que Bonet desenvolve junto com Ferrari Hardoy e Vivanco em 1949, o tema da habitação é colocado junto de outros programas, assim como em Barrio Sur, e a articulação entre estes elementos se dá através de um sistema pedestre no nível térreo, pensado como uma grande estrutura de passeios cobertos. Tal elemento interliga os blocos de habitação ao mesmo tempo em que dá suporte a comércios e serviços, e ao estabelecimento de praças, esplanadas e equipamentos esportivos. Para Cabral (2010, p. 93), Bajo Belgrano se faz mais complexo em relação ao uso do térreo e ao espaço aberto e não comprova esta visão esquemática da cidade moderna, ainda que para Bonet a área verde dedicada ao projeto se coloque como um excesso a ser corrigido (BONET in BOBZIN, 1983, p. 46). E é pela introdução da vaca capaz de conter o verde que a proposta para o Barrio Sur faz avançar o sistema de Bajo Belgrano, montando um tipo de topografia construída que possibilita que a rede de movimento pedestre se desenvolva de forma mais expandida, ocupando vazios que em Bajo Belgrano eram preenchidos pela natureza.

Isto se manifesta de modo mais claro quando as representações gráficas dos dois projetos são comparadas (Fig. 5 e 6 ). Nos desenhos para a proposta de Bajo Belgrano, a natureza se apresenta como algo intrínseco do lugar, das margens de um Rio da Prata em que a intervenção ocorre somente na medida necessária: onde a rede pedestre e seus desdobramentos perpassam, onde o térreo dos edifícios compõem os 
espaços de recreação. O contrário aparece para Barrio Sur, em que as perspectivas demonstram uma natureza circundada pelo projeto, contida, e já não mais tão verde, exuberante e natural. Existe uma mudança frente à relação cidade e natureza proposta, que troca o verde-natural por um verde-artificial. Diferente de Bajo Belgrano, o objeto de estudo sobre o qual as relações são pensadas não é a natureza de um lugar pouco urbanizado, mas sim a própria cidade que ali está a ser revisada pela proposta.
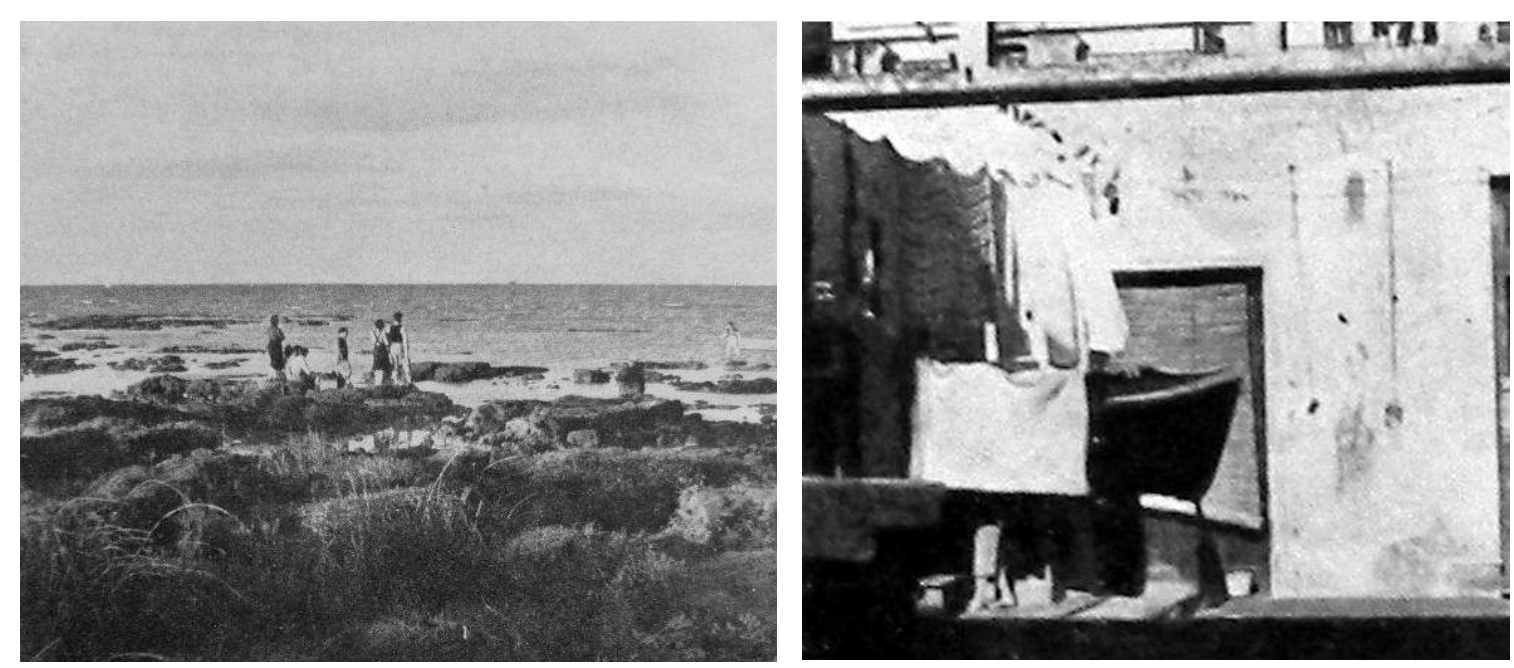

Figura 5 - Aspectos da área de projeto: na esquerda, Bajo Belgrano; na direita, Barrio Sur.

(EPBA, 1949; MIRADOR, 1957, p. 70)
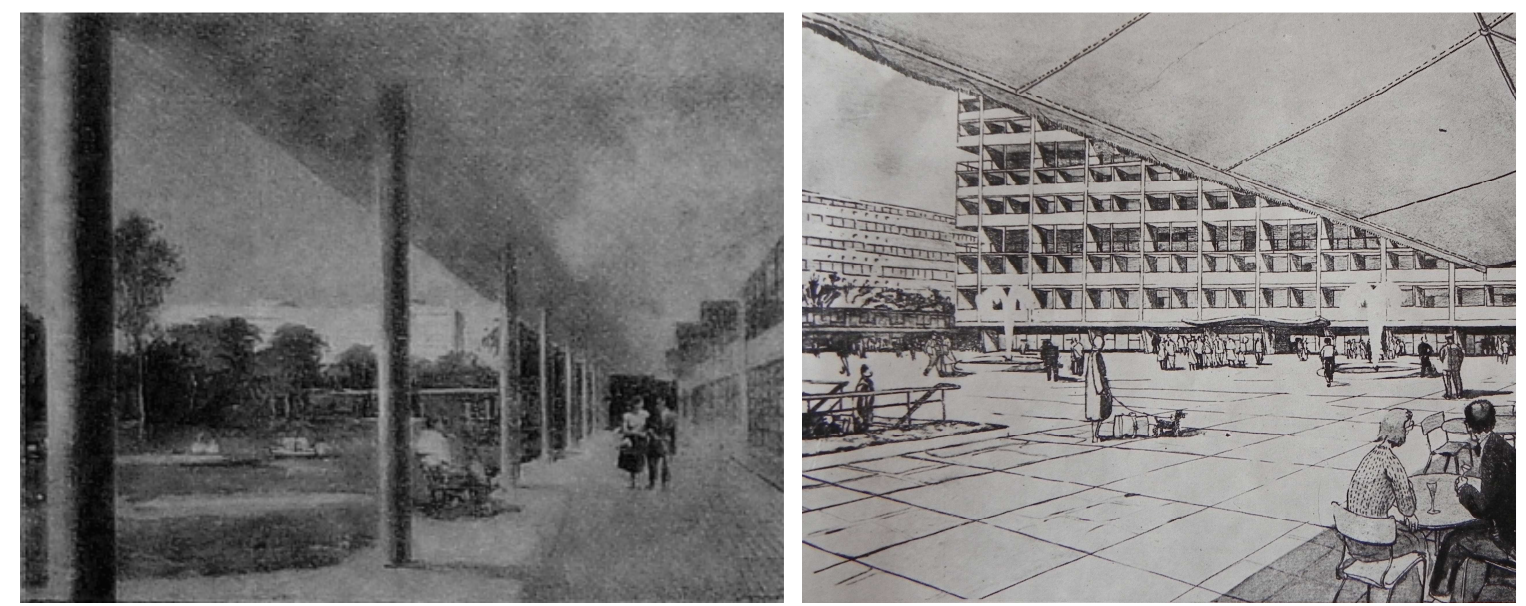

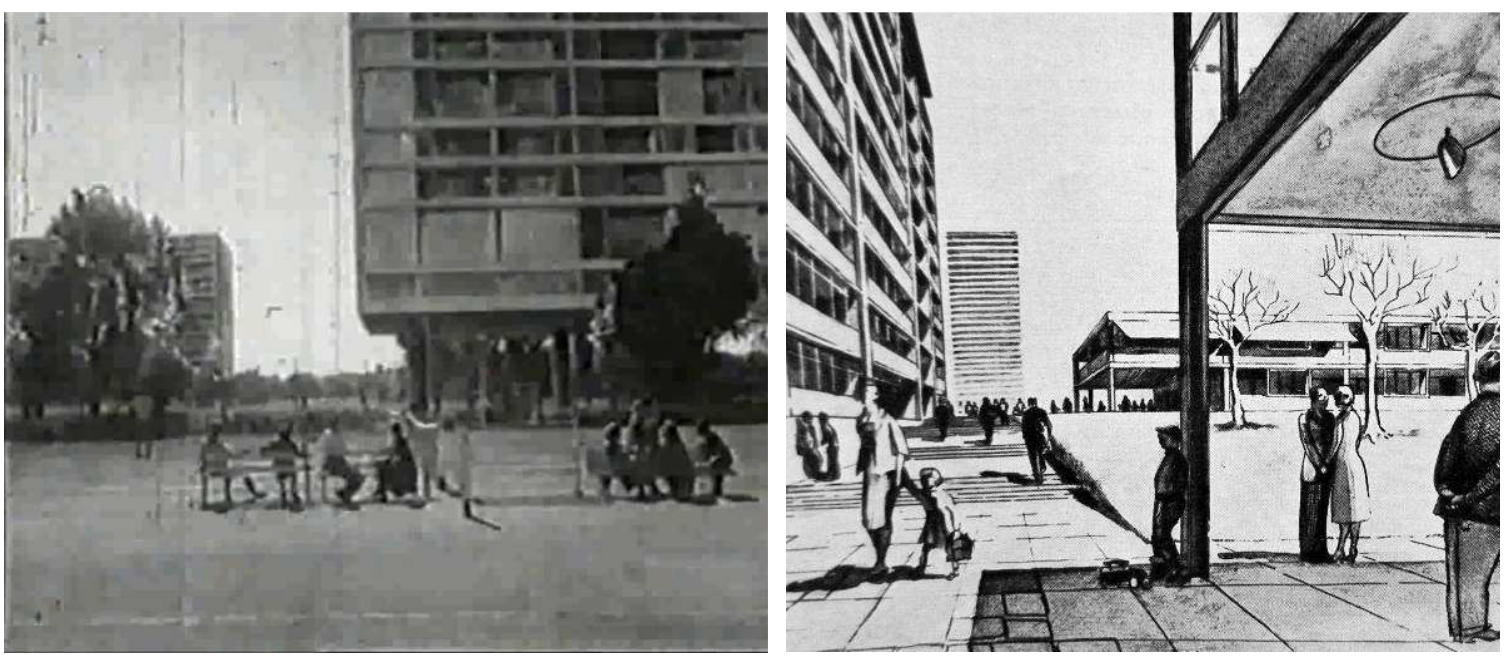

Figura 6 - Rede de movimento pedestre: na esquerda, Bajo Belgrano; na direita Barrio Sur.

Fonte: EPBA, 1949; BHN, 1957; MIRADOR, 1957, p. 69

Desta forma, na proposta para Barrio Sur a rede de movimento pedestre não é pensada como um grande elemento como acontece em Bajo Belgrano, sendo constituída pelos próprios componentes da cidade, tanto edificações quanto praças, misturando-se às vezes ao espaço aberto, às vezes ao espaço construído intermediado pela vaca. Como demonstra o diagrama da circulação pedestre (Fig. 7), o térreo do espaço construído é parte da formatação do percurso, que integra o térreo da torre, bem como os bordos da greca e da vaca, formando uma gradação entre espaços abertos, e abertos e cobertos, que medem 8,50 metros entre edifícios e 3,50 metros entre áreas verdes. Assim, os três elementos componentes da cidade - a torre, a greca e a vaca - devem ser entendidos como peças urbanas, ou, como Bonet (1949, p. 24) explica, "fragmentos de cidade" e não em edifícios no sentido tradicional da palavra ${ }^{11}$. Tendo esta compreensão, assume-se a capacidade destas estruturas de definir questões urbanas como, por exemplo, a separação entre as circulações de veículos das de pedestres, ou a sua união quando conveniente (Fig. 8); ou a continuidade da rede pedestre para além do térreo, ascendendo verticalmente.

\footnotetext{
11 No texto Nuevas precisiones sobre arquitectura y urbanismo, Bonet explica: "Como conclusión, podemos precisar, que la evolución paralela de esos tres procesos que hemos analizado nos llevará al planeamiento de tres dimensiones, en que los edificios serán concebidos urbanísticamente, es decir, no serán verdaderos edificios en el sentido tradicional de la palabra, sino fragmentos de ciudad, dentro de los cuales se desarrollarán las diversas actividades humanas." (BONET, 1949, p. 24).
} 


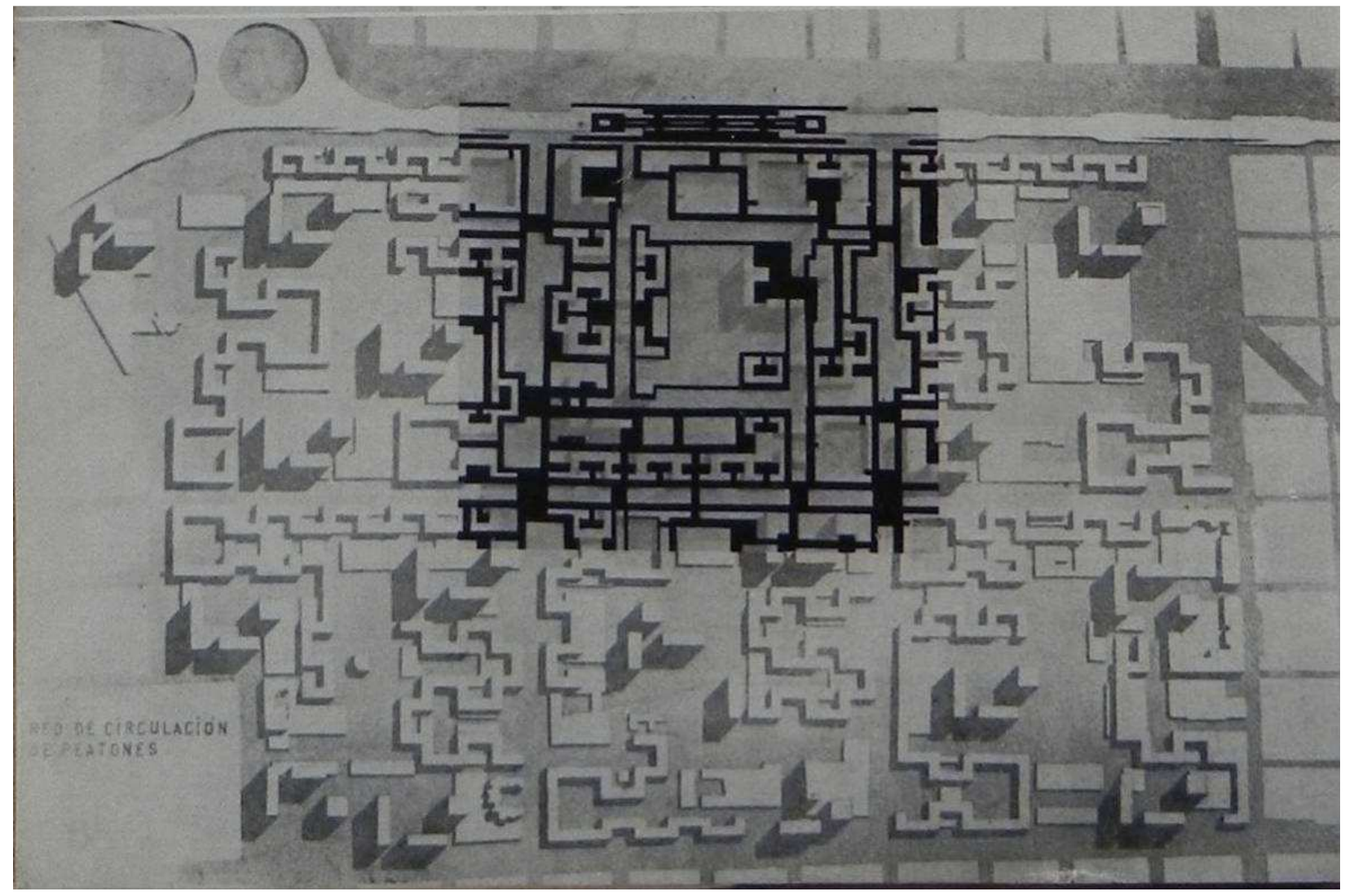

Figura 7 - Rede de movimento pedestre de um dos bairros planejados, Barrio Sur.

Fonte: CUADERNOS DE ARQUITECTURA, 1959, p. 10
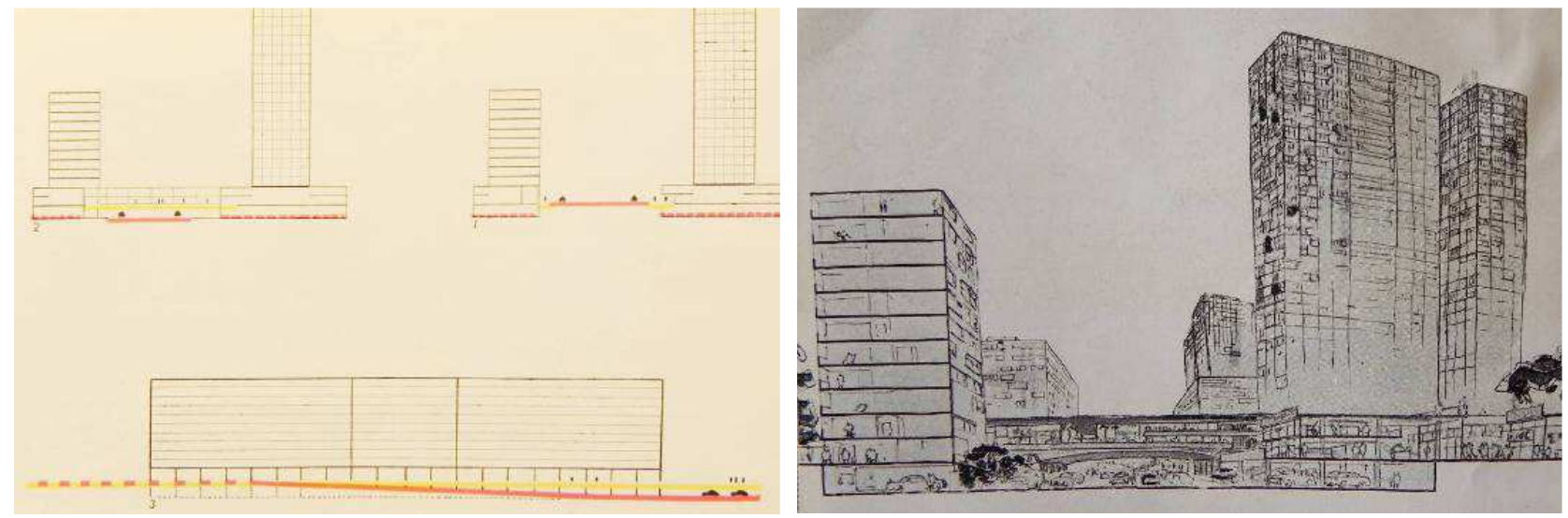

Figura 8 - Rede pedestre em cortes esquemáticos, Barrio Sur.

Fonte: MIRADOR, 1957, p. 74; REVISTA NACIONAL DE ARQUITECTURA, 1956, p. 38

\section{Da vaca à torre: a dimensão vertical na rede}

Pela compreensão dos edifícios como fragmentos de cidade, a rede pedestre iniciada no térreo pode ser continuada de forma controlada na torre ou na greca. Neste sentido os corredores que dão acesso às habitações podem ser entendidos como corredores não pertencentes apenas ao edifício, mas como "ruas elevadas" que pertencem também à cidade, remetendo a uma ideia de "empilhamento da quadra convencional" como explica Cabral em seu artigo Anatomia da rua elevada. O projeto 
da circulação coletiva como investigação formal e programática na cidade moderna (2009). No artigo, Cabral analisa as diferentes formas em que o percurso elevado se materializa em proposições modernas, existindo exemplos em que estas passagens são internas, externas, ou verdadeiras tramas no ar que recuperam o sentido da rua como espaço de socialização. Na proposta para o Barrio Sur este percurso elevado ocorre nas passarelas que cruzam as ruas de tráfego rápido, permitindo a continuidade da rede pedestre pelo plano, na greca pelo acesso às habitações, e também na torre.

Ao se somar com a rede pedestre no térreo, esta circulação elevada é parte de uma preocupação de Bonet em separar o trânsito de carros do trânsito de pedestres, afirmando que "as ruas que antes estavam à escala do homem [...], converteram-se em simples canais de trânsito" (BONET, 1957, p. 67, tradução nossa) e não mais figuram como espaços de socialização, ideia que pretende ser resgatada pelo plano (BONET, 1957, p. 70). A separação entre carros e pedestres não ocorre de modo integral em todo o plano, existindo quando a circulação de pedestres no térreo entra em conflito com a circulação de veículos das vias de trânsito rápido, as quais definem os limites dos bairros. Para tanto, a solução encontrada é elevar a rede pedestre pelo uso de passarelas que atravessam as circulações de veículos; ou mantê-la no mesmo nível quando a topografia do sítio permite que a circulação de veículos ocorra a um nível abaixo. Quando a rede pedestre se eleva, essas passarelas são aproveitadas para a instalação de comércios, constituindo-se também em edifícios, ou em pedaços de vaca. As demais porções do plano são resolvidas pela convivência entre pedestres e veículos, seja nos pontos de intersecção com a cidade existente, seja nas áreas de estacionamento distribuídas pelo plano onde os veículos circulam com velocidade reduzida.

Ainda que pouco mencionada na memória descritiva do plano e nas revistas em que o plano foi publicado à época, a greca tem importância na promoção da continuidade da rede pedestre pelo plano. Horizontalmente é ladeada pelo comércio, articulando junto com a vaca um importante movimento pedestre no térreo formado por espaços abertos e cobertos, próximos da ideia do pórtico que forma galerias (BHN, 1957); combinando o plano horizontal ao vertical, é o elemento capaz de ultrapassar o arruamento que define os bairros, elevando-se sobre ele e conectando quando necessário um bairro a outro através da habitação. Pela característica diretiva do plano, a organização interna da greca não foi explicitada, mas é possível estabelecer relações entre ela e a ideia proposta pelo edifício redent de Le Corbusier. É importante notar que a greca não assume sozinha a tarefa de compor o ritmo do 
tecido urbano, o qual se realiza em conjunto com a torre. Em relação a esta última, Bonet teve a oportunidade de melhor defini-la, projetando um trecho que caracterizaria a primeira etapa a ser executada do plano. Os edifícios em torre desta etapa seriam realizados pelo próprio Banco Hipotecário Nacional, e poderiam servir de modelo para as etapas futuras a serem completadas ao longo dos dez anos de obra (BHN, 1957).

A torre ocorre no plano em grupos compostos por três torres cada, que partilham de uma mesma altura, montando um conjunto passível de variabilidade quanto às relações montadas entre si. Estes conjuntos se implantam no plano de modo a manter relações com o espaço aberto principal de cada bairro, o que permitiria também valorizar este espaço aberto e a própria arquitetura dos edifícios (BHN, 1957). Cada conjunto é formado por uma torre quadrada e duas torres retangulares, sendo uma de maior fachada para a orientação leste-oeste, e outra para a orientação norte-sul. Entre as torres retangulares desenvolvidas por Bonet (Fig. 9), observam-se dois tipos de abordagem das circulações, ou ruas elevadas, que aproveitam as potencialidades das diferentes orientações. Na torre leste-oeste, a rua elevada é internalizada, configurando-se em uma rua interior, o que permite às unidades um melhor uso das duas orientações ensolaradas; na torre norte-sul, a fachada sul, que é caracterizada pela pouca presença do sol, é em parte ocupada pela rua elevada, que se faz exteriorizada, decisão que retoma algumas experiências que Bonet realiza anteriormente ${ }^{12}$. O agrupamento de torres formado é possível de ser pensado como um desmembramento do City-Block de planta cruciforme pensado por Wladimiro Acosta (1928-1930); ou ainda, frente à estratégia de Bonet de posicionar a circulação em relação à melhor orientação para as unidades, faz pensar as torres como próximas à lógica do redent, que Le Corbusier desenvolve no projeto Ville Radieuse (1930), assim como a greca.

\footnotetext{
${ }^{12}$ Esta mesma estratégia pode ser encontrada nos projetos Conjunto Habitacional Casa Amarilla (1943), Bajo Belgrano (1949), Conjunto Habitacional T. O. S. A. (1952), e até mesmo no edifício de ateliês na esquina das ruas Paraguay e Suipacha (1939).
} 

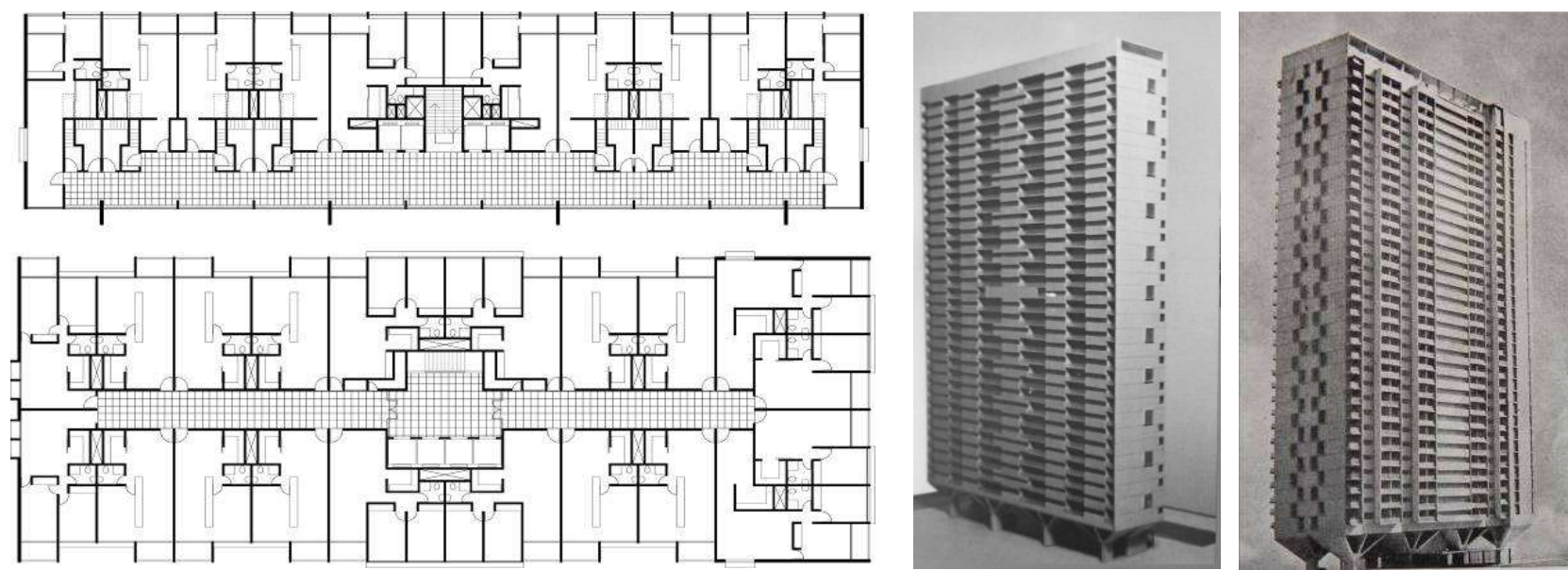

Figura 9 - Da esquerda para a direita: redesenho das torres norte-sul, leste-oeste; maquete das torres norte-sul, leste-oeste, respectivamente.

Fonte: ALVAREZ; ROIG, 1996, p. 141; BHN, 1957

De modo geral, o sistema armado pela torre, greca, e pela articulação de ambos através da vaca, monta um conjunto a ser compreendido em três dimensões. Pela junção do plano vertical, possibilitado pela torre, pela greca, e pelas passagens em diferente nível, com o plano horizontal configurado pela vaca, pelas preexistências e pelo térreo dos edifícios, afirma uma lógica distinta daquela colocada pela cidade tradicional. No plano para o Barrio Sur, os edifícios e a cidade se confundem, estabelecendo-se como estruturas capazes de interferir no térreo e de expandir os espaços de socialização. Desta forma, o plano é um testemunho gráfico em concordância com o discurso de Bonet da época, o qual afirmava que "os grandes elementos arquitetônicos [...] formarão a verdadeira estrutura da cidade, da mesma maneira que em nosso atual e anacrônico urbanismo de duas dimensões." (BONET 1949, p. 24, tradução nossa).

\section{Conclusão}

O artigo procurou entender o Plano de Remodelação para o Barrio Sur proposto por Antonio Bonet como parte integrante de um contexto histórico e político de valorização do sul da cidade de Buenos Aires, cujo modo dessa valorização se deu pelo uso da habitação como programa ativo e imprescindível ao centro. A estratégia de colocar a habitação como programa principal no centro não se faz de modo a isolálo em sua função, mas de modo a articulá-lo com outros programas e com a cidade existente, tendo como consequência uma proposição não da cidade da Carta de Atenas, de funções separadas por zonas, mas o contrário, uma cidade em que estas dimensões convivem, ainda que separadas pelo plano vertical. Esta atitude se vê vinculada a repensar a cidade que ali existe, em sua forma e escala, e que se 
configura no ponto de partida da proposição, demandando respostas em termos de elementos capazes de costurar de modo coerente uma nova lógica urbana sobre a antiga.

Para tanto, a estratégia desenvolvida por Bonet é a de sobrepor e correlacionar três elementos de escalas distintas - a torre, a greca e, sobretudo, a vaca - o que resulta em um novo tecido urbano, cujo espaço aberto derivado é colocado em investigação quanto a sua escala e composição, e diverge do entendimento comum que se tem do espaço aberto da cidade moderna como área reduzida apenas ao verde. Parte importante da investigação deste espaço aberto é a montagem de um sistema pedestre, intermediado pela vaca. Elemento que é a novidade em relação à proposição anterior de Bajo Belgrano, em que a preocupação com a montagem de uma trama pedestre também aparece.

\section{Referências}

ALVAREZ, Fernando; ROIG, Jordi. Antoni Bonet Castellana 1913-1989. Barcelona: Colegio de Arquitectos de Catalunya/ Ministério de Fomento, 1996. 227 p.

Antonio Bonet Castellana. Barcelona: Santa \& Cole, Centre d'Estudis de Disseny ETSAB, Edicions UPC, 1999. 280 p.

BALLENT, Anahi. Las estéticas de la política: arquitectura y ciudad. El peronismo em Buenos Aires 1946-1955. In: V Jornadas de Teoria y Historia de las Artes: arte y poder, 1988. Anais... Buenos Aires: CAIA, 1988. p. 116-125.

. Las huellas de la política. Vivienda, ciudad, peronismo em Buenos Aires, 1943-1955. Bernal: Prometeo 3010, 2009. 280 p.

BANCO HIPOTECARIO NACIONAL. Plan de Remodelacion de la Zona Sudeste de la Capital Federal. Estudio urbanístico, legal y financiero. Buenos Aires: Banco Hipotecario Nacional, 1957. 49 p.

BASTLUND, Knud. Jose Luis Sert, architecture, city planning, urban design. Nova Iorque: Praeger, 1967. 244 p.

BLAS, Alvaro. La Remodelación del Barrio Sur. Leoplan, Buenos Aires, n. 352, p. 6-9, ago. 1957.

BOBZIN, Alejandro. Encuentros: Antonio Bonet. Dos Puntos, Buenos Aires, n. 10, p. 43-50, jul. 1983.

BONET, Antonio. Nuevas precisiones sobre arquitectura y urbanismo, 1949, p. 24. Arquivo Antoni Bonet i Castellana. COAC, Barcelona. Acesso: fev. 2013. . Plan de Remodelamiento de la Zona Sud de Buenos Aires. Mirador, Buenos Aires, n. 2, p. 63-77, jun. 1957. 
- Remodelamiento de la Zona Sur de Buenos Aires. Cuardenos de Arquitectura, Barcelona, n. 37, p. 8-13, 30 trimestre, 1959.

. Antonio Bonet, o el espíritu del Movimiento Moderno. Summa, Buenos Aires, n. 188 , p. 19-22, jun. 1983. Entrevista concedida a Alberto Petrina.

BOYER, Hebe. Una ciudad moderna, confortable, optimista. Para ti, Buenos Aires, n. 1795, p. 41-42, nov. 1956.

CABRAL, Cláudia P. C. A cidade vertical: Conjunto Habitacional Rioja, Buenos Aires, 1968-1973. Arqtexto, Porto Alegre, n. 12, p. 98-131, 2008.

Anatomia da rua elevada: o projeto da circulação coletiva como investigação formal e programática na cidade moderna. In: IV PROJETAR. Projeto como investigação: ensino, pesquisa e prática, 2009, São Paulo. IV PROJETAR. Projeto como investigação: ensino, pesquisa e prática. São Paulo: FAU-UPM; Editora Alter Market, 2009. p. 1-23

. Uma máquina para jogar em Buenos Aires 1938-1978. Arqtexto, Porto Alegre, n. 17, p. 78-103, 2010.

COMAS, Carlos E. D. Cidade funcional versus cidade figurativa. A partir do bairro. AU, São Paulo, n. 9, p. 64-66, dez-jan. 1986-87.

DIRECCIÓN GENERAL DE ESTADÍSTICA Y CENSOS. Población censada, superficie y densidad poblacional según barrio. Ciudad de Buenos Aires. Año 2001. In: Buenos Aires Ciudad. Disponível em: <http://www.buenosaires.gob.ar/areas/hacienda/sis_estadistico/banco_da.php?tema $=8>$. Acesso em: 18 jun. 2013.

ESTUDIO DEL PLAN DE BUENOS AIRES. 3ra. Fundación de Buenos Aires. Buenos Aires: Vigor, 1949.

. Urbanización del Bajo Belgrano. Un barrio para 50.000 habitantes. Revista de Arquitectura, Buenos Aires, n. 369, p. 1-75, 1953.

GORELIK, Adrián. La Grilla y el Parque. Espacio publico y cultura urbana em Buenos Aires, 1887-1936. Bernal: Universidad Nacional de Quilmes, 2010. 456 p. KATZENSTEIN, Ernesto; NATANSON, Gustavo; SCHVARTZMAN, Hugo. Antonio Bonet: Arquitetura y Urbanismo en el Rio de la Plata y España. Barcelona: Espacio Editora, 1985. 266 p.

LE CORBUSIER et al. Plan Director para Buenos Aires. La Arquitectura de Hoy, Buenos Aires, n. 4, p. 2-53, 1947.

. La Ciudad del Futuro. 2a ed. Buenos Aires: Ediciones Infinito, 1971. 181 p. 
LIERNUR, Jorge F.; PSCHEPIURCA, Pablo. La Red Austral: obras y proyectos de Le Corbusier y sus discípulos en la Argentina (1924-1965). Bernal: Prometeo Libros, 2008. 432 p.

LIERNUR, Jorge F. Las "villas miseria", el "Barrio Sur" y la "Revolución Libertadora". Uma aproximación a la más importante propuesta de vivienda colectiva de Antonio Bonet. In: 1ras Jornadas de Historia y Cultura de la Arquitectura y la Ciudad. Historia, estética y teorias de la arquitectura: Grandes obras de la arquitectura en la Argentina (1910-1980), 2011. Anais... Buenos Aires: Universidad Torcuato di Tella, 2011. p. 84-99.

LUZARTE, Julián. El Buenos Aires Futuro. Esto es, Buenos Aires, n. 134, p. 22-24, ago. 1956.

PROJETO de Urbanização para Buenos Aires. Habitat, Rio de Janeiro, n. 47, p. 62-75, mar-abr. 1958.

MONTEYS, Xavier. La Gran máquina: la ciudad en Le Corbusier. Barcelona, Ediciones del Serbal, 1996. 317 p.

ORTIZ, Federico F.; BALLDELLOU, Miguel Angel. La obra de Antonio Bonet. Buenos Aires: Ediciones Summa, 1978. 135 p.

PLAN San Telmo, una Gran Obra. Esto es, Buenos Aires, n. 173, p. 24-26, jul. 1957.

RAMOS, Ignacio. Noticia sobre Urbanismo. Revista Nacional de Arquitectura, Madri, n. 178, p. 35-39, out. 1956.

SANTIAGO, Iñigo de. El Barrio Sur de Buenos Aires va a ser demolido totalmente y alzado em un plazo de diez años. Mundo Hispánico, Madrid, n. 104, p. 14-17, nov. 1956.

SAN Telmo, Barrio interdicto. Qué sucedió en sete dias, Buenos Aires, n. 107, p. 16-18, out. 1956.

SLUM-SANIERUNG in Buenos Aires. Wohnungen für 400000 Menschen in der Nähe der City. Bauen und Wohnen, Munique, n. 3, p. 74-78, mar. 1958.

YUJNOVSKY, Oscar. Revisión histórica de la política de vivienda en la Argentina desde 1880. Summa, n. 72, p. 17-18, fev. 1974. 